\title{
More Than a Backdrop: Understanding the Role of Communities in Programming for Adolescent Girls-Action Guide
}

\author{
Sarah Blake \\ Population Council \\ Miriam Temin \\ Population Council
}

Follow this and additional works at: https://knowledgecommons.popcouncil.org/departments_sbsr-pgy

Part of the Civic and Community Engagement Commons, Demography, Population, and Ecology Commons, Family, Life Course, and Society Commons, and the Gender and Sexuality Commons How does access to this work benefit you? Let us know!

\section{Recommended Citation}

Blake, Sarah and Miriam Temin. 2019. "More Than a Backdrop: Understanding the Role of Communities in Programming for Adolescent Girls-Action Guide." New York: Population Council. 


\section{ACTION GUIDE}

\section{MORE THAN A BACKDROP}

Understanding the role of

communities in programming

for adolescent girls

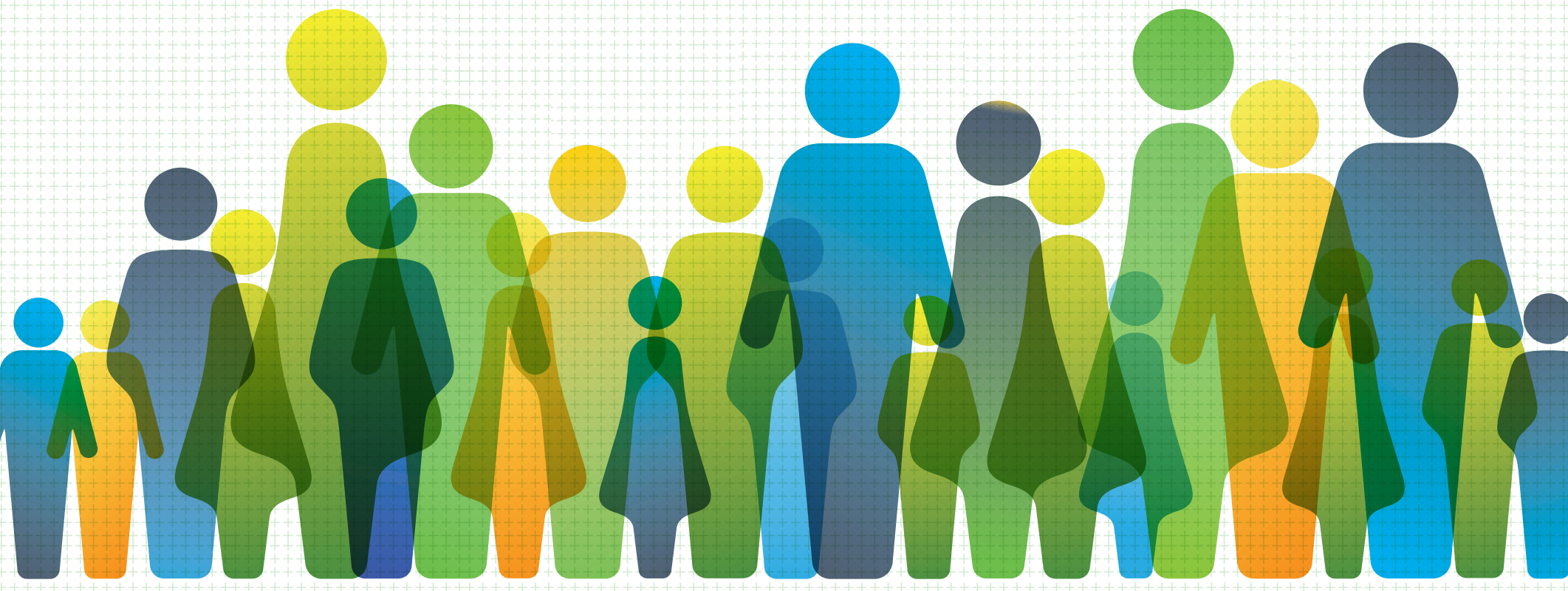




\section{WHY COMMUNITIES?}

Many interventions to reduce girls' risks and increase their opportunities center on community-based clubs or "safe spaces." Programs that use this approach encourage girls to build valuable relationships, skills, knowledge, and other such assets to prepare them to make and act on decisions about their own lives. A growing body of evidence shows that these types of programs can improve girls' chances in life, with positive effects on health, educational achievement, job opportunities, and safety. ${ }^{1}$

Evidence shows that no "one size fits all" type of program achieves the same effects for all girls in all places. ${ }^{2}$ And one reason for mixed effects is the critical but often overlooked role that communities play in shaping how workplans evolve into real-world action. The structural and social features of a girl's community play a critical role in determining what effects programs can achieve.

Girls' communities include both the physical spaces they must navigate and adults and peers who shape their beliefs about marriage, work, and education. In other words, the community is an active program participant, and its influence on girls' programming is just as important as mentors, program staff, and other people who have a formal role in implementation.

Early in the process of program design, access to information about the community may smooth implementation and enhance the chances of success. Having answers to key questions can help program staff adapt to the specific dynamics of the communities where they work, and make informed decisions at the early stages of program design. This can influence topics like figuring out who is eligible, selecting program content, assessing the community's needs, providing mentor supervision, and monitoring the program.

\footnotetext{
Erulkar, Annabel. 2014. "What is an Asset?" Infographic. popcouncil.org/uploads/pdfs/2014PGY_BuildingAssetsThrive_AssetsInfographic.pdf. Population Council. 2018. "Delivering Impact for Adolescent Girls: Emerging Impact for Adolescent Girls." popcouncil.org/uploads/resources/2018PGY_GIRLCenterSynthesis.pdf

Temin, Miriam, Sajeda Amin, Thoai D. Ngo, and Stephanie Psaki. 2018. "How to give adolescent girls voice, choice, and control," Stanford Social Innovation Review, ssir.org/articles/entry/how_to_give_adolescent_girls_voice_choice_and_control.
}

This Action Guide focuses on five key questions, offers tips on how to find answers, and provides realworld examples that demonstrate how to use community-level insights for action for adolescent girls. It was written for people who design, manage, and assess communitybased programming.

In communities, girls' programs often work through "safe spaces" or girls' clubs, which typically include regular meetings led by a local mentor who delivers information to participants. ${ }^{3}$ This guide is also relevant to programs that engage girls through other channels, including schools, and it can be useful for community-based programming with boys and parents. 


\title{
How many girls live in a given community?
}

\author{
Answering this question can help program staff decide how \\ many meeting spaces and girls' groups to establish, and where.
}

Identifying the number of girls in a given community is important for defining the criteria used to determine which girls to target, and should reflect both geographic and demographic features. Population density, how far girls are allowed to travel, and recruitment goals should also inform how the targets are defined.

In a sparsely populated rural area, some communities are too small for even a single girls' group of 15-30 members, while a dense peripheral or urban setting may be home to enough girls to form several groups. Once they know how many girls live in a community, program staff may decide to increase the number of clubs or narrow the eligibility criteria for a large community, or negotiate with authorities in two small villages to set up a club that serves girls in both.

Where to find answers: Census reports may give estimates of the number of people who live in a given village, town, or city, while sources such as Demographic and Health Surveys (DHS) or Multi-Indicator Cluster Surveys (MICS) can provide critical insights on how girls' risks vary according to urban or rural residence. Such sources can provide estimates of the size of typical households and the proportion of the total population that is adolescent girls aged 10-19 years, which can help determine how many girls' groups to establish for a set number of households.

Part of the work of defining a realistic "community" falls to the program: rather than selecting a name on a map and assuming that one club will be sufficient for all girls in the target group, program staff should consider official government and traditional or locally defined boundaries and gather local information using tools like the Girl Roster ${ }^{\mathrm{TM}}$. They should also consider the possibility that girls' movements might be restricted to a small area close to home. ${ }^{4}$ These insights can help determine where it is necessary to establish multiple service areas sufficient numbers of girls in a single town.

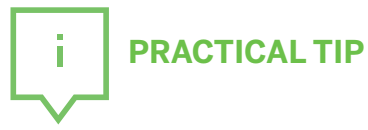

The Population Council's Girl Roster ${ }^{\mathrm{TM}}$ tool $^{5}$ was developed to equip program staff to gather and use information about program communities. The Roster is conducted in three steps:

1) Program staff visit every household in a set geographic area to conduct a brief survey with an adult and collect basic information on all girls in the household.

2) Survey results are compiled and automatically sorted to produce a visual snapshot of the total number of girls, organized by important characteristics such as age and schooling status.

3) Staff use these snapshots to plan their programs, beginning with the question of which girls to recruit and what strategies they will use to recruit them.

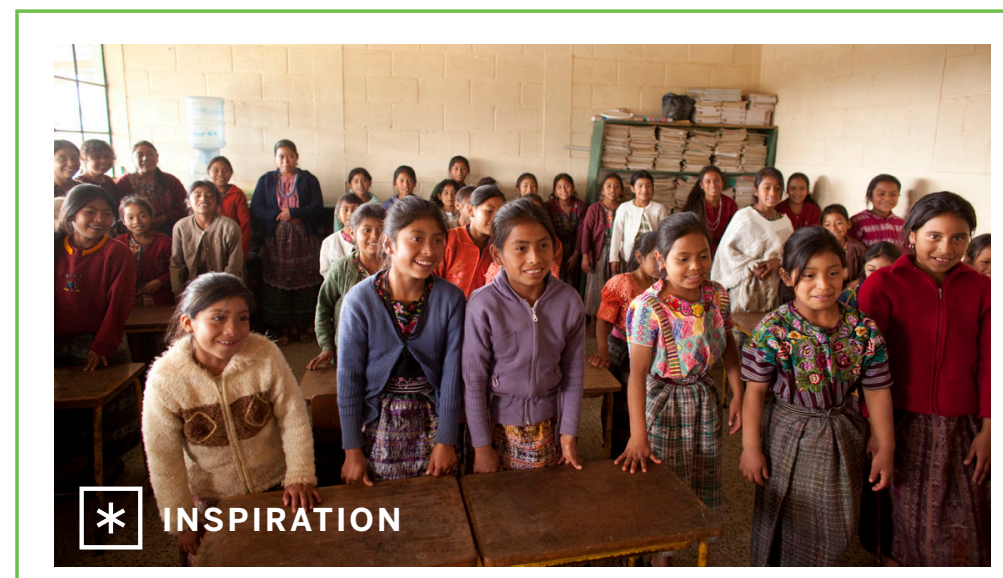

Abriendo Oportunidades, (“Opening Opportunities”) a program to empower indigenous girls in rural Guatemala, works in communities the size of a typical village or the area served by one primary school: 500 to 1500 people. In this setting, census data show that 10-19-year-old girls make up around 10 percent of the population, which means that program staff can assume that 50 to 150 eligible girls live in a program community. This basic information allows staff set realistic targets for recruitment. It also helps them avoid common pitfalls, such as failing to recruit enough girls to form a meaningful peer group or recruiting too many girls and having to turn prospective participants away.

\footnotetext{
4 Hallman, Kelly K. et al. 2014. "The shrinking world of girls at puberty: violence and gender-divergent access to the public sphere among adolescents in South Africa." Global Public Health 10(3): 279-95.

5 For more information on the Girl Roster ${ }^{\mathrm{TM}}$ : popcouncil.org/research/girl-roster.
} 


\section{Is the community urban, peri-urban, or rural? Is it formal or informal?}

\section{Beyond basic differences in number of residents and population density between urban, peri-urban, and rural communities, other variations are also vital to consider.}

Features like the degree and type of community structures also influence girls' lives.

For example, whether most residents rely on agriculture, trading, or formal wages for income; if schools are within walking distance of girls' homes; and what sort of leadership roles, power, and responsibilities prevail. Shedding light on these features can be critical to adapting program design to girls' lives. This information should influence decisions on topics like eligibility criteria, group structure, the timing of meetings, or tactics for engaging the community.

Where to find answers: Urban and rural communities are easy to identify using government population data. Understanding peri-urban locations-which are often informal-may be challenging since they do not appear on maps and lack clear boundaries and governance structures. NGOs and service providers may offer initial insights about such communities. Consultations with informal community groups, religious leaders, and the girls themselves can provide a more complete picture.

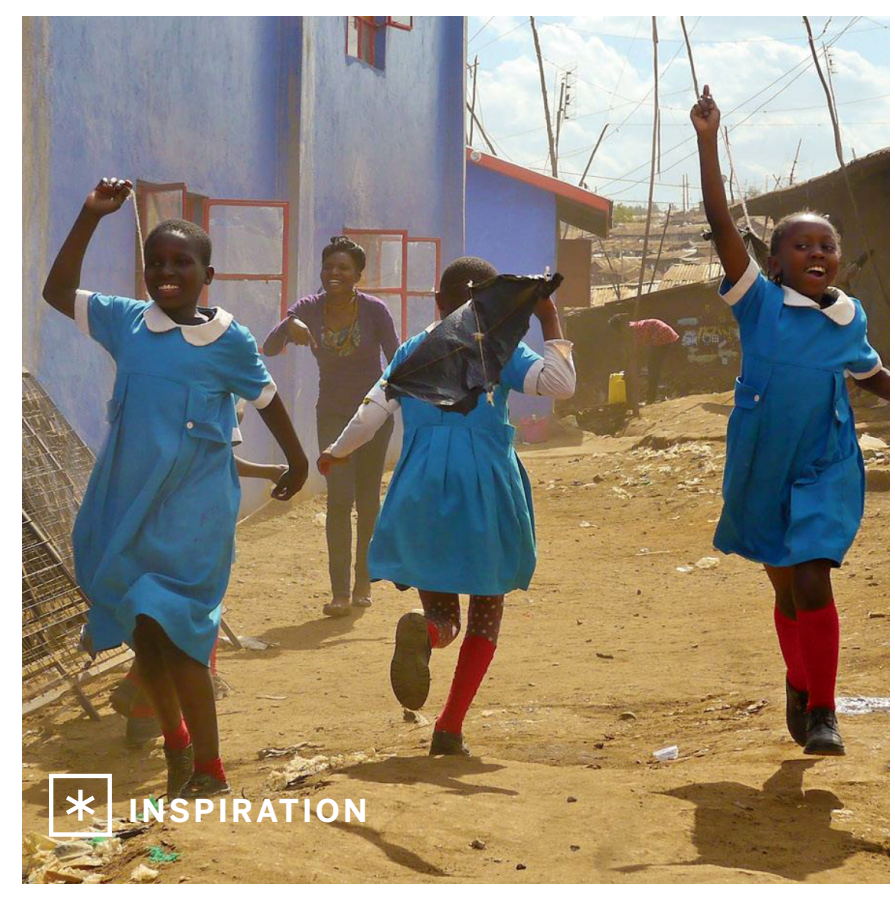

The Adolescent Girls Initiative-Kenya (AGI-K) operated girls' clubs in both urban and rural sites with girls $11-15$ years old. Within each site, girls were recruited and assigned to one of two groups of 15-30 participants with certain characteristics in common. In AGI-K's densely populated urban sites, many girls fall into the eligible age group (11-15) and most of them are enrolled in school. In these areas, girls were split into younger (11-12) and older (13-15) groups.

By contrast, in AGI-K's sparsely populated rural areas, substantial proportions of girls in this age range are not enrolled in school. Here, girls were assigned to groups by schooling status-groups for in-school and out-of-school girls-rather than by age. This encouraged in-school girls to support each other to continue pursuing an education; the out-of-school groups provided otherwise isolated girls a space to build social ties while using content that is tailored to lower literacy levels. 


\title{
How stable or cohesive is a community? Who is considered a "community member"?
}

\author{
Community stability and degree of mobility influence \\ what strategies are likely to attract and retain eligible girls.
}

Girls may spend their entire childhood in a single, stable community or move-for school or employment, in response to a disaster, or to escape conflict. When they move, they may make the journey alone or with parents. They can arrive in a well-known, stable community or an unfamiliar informal settlement, where they might belong to the dominant ethnic group or a small minority. These factors all influence how girls experience a new community; they also influence the ease of recruiting the intended beneficiaries into the program. In cohesive, stable settings, a contract between program and community representatives may be a powerful tool to support girls' participation. On the other hand, in informal settlements, such as urban slums, the community may not recognize any particular set of adults as authorities, so finding representatives to speak for the community may be a challenge.

Even in otherwise stable settings, long-term residents may not consider domestic workers, refugees, internally displaced people, students, or laborers as full members. Additional effort may be needed to identify such girls and build support for their participation in programs. In settings where girls are highly mobile and may only stay for a few months at a time, it may make sense for a program to offer a few core lessons early on, to ensure that the largest number of girls benefit.

Where to find answers: Sources of information on the nature and stability of community structures, such as traditional leadership councils, and girls' positions within the community include household surveys, and interviews with health providers, teachers, young women, or people working with other NGOs. Engaging girls in exercises to identify their neighborhood assets-by mapping their communities and social networks-can provide additional insights.

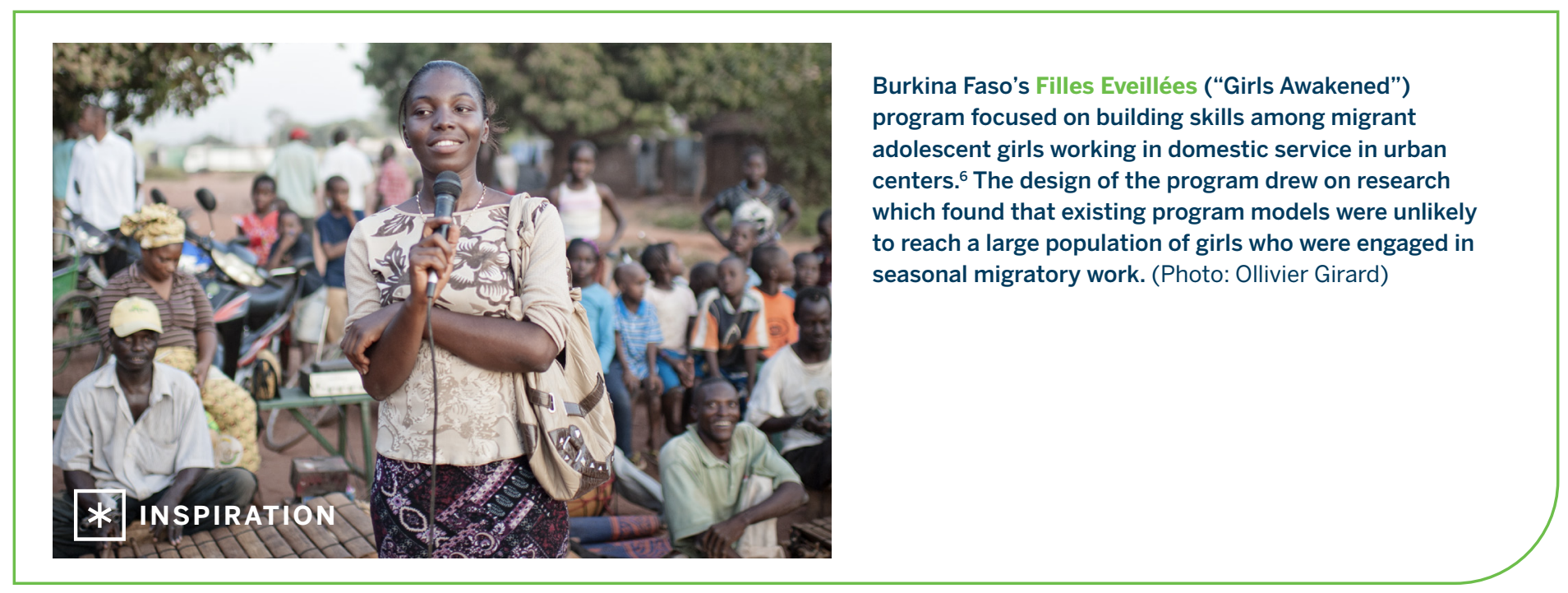

6 Engebretsen, Sarah. 2013. “Designing, Implementing, and Evaluating a Targeted Evidence-based Intervention for a Vulnerable Subgroup of Girls.” popcouncil.org/uploads/pdfs/2013PGY_FillesEveilleesCaseStudy.pdf 


\section{What resources exist for girls in the community, and who has access to them?}

\section{Collecting information about existing resources can provide important insights both on the resources themselves and how a girls' program will be perceived.}

\begin{abstract}
Where people hold NGO programs in high regard, staff can establish relationships with these programs to build trust with community members. If community members feel NGOs have ignored their needs in the past, parents and girls may see little value in girls' participation. Communities with few resources for young people may be especially wary of programs that appear to prioritize girls over boys.
\end{abstract}

Where to find answers: Interviews with parents, teachers, NGO staff, women's leaders, and health providers can shed light on what resources exist, which boys or girls access them, and attitudes about NGOs and government services. Exercises that engage girls, such as physical and social mapping to identify what resources and activities they do and do not attend, and why, are informative. Information on who girls rely on and trust within the community may provide additional value. Ongoing consultations with members of these groups can help build trust and lend important nuance to program data.

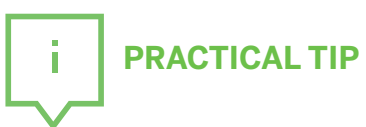

Community members often face many challenges and need more than what one program can offer to deal with all their issues.

It is important to be clear from the beginning about the program goals, setting reasonable expectations about what a program can provide for girls and other community members. For instance, a girls' club may provide homework support and encourage positive attitudes about girls' education, but not reduce financial or other barriers to schooling. While an assessment of the community's needs and other research activities are valuable first steps to meaningful program design and engagement, it is critical to set realistic expectations about their purpose: how the information will be used, who will benefit from a program, and what that "benefit" might look like.

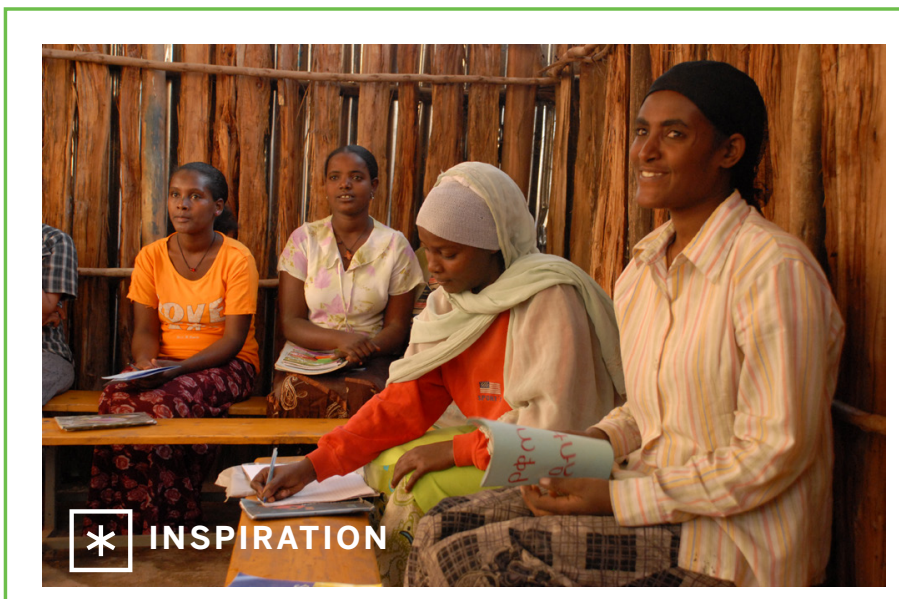

The Berhane Hewan7 ("Light for Eve”) program in Ethiopia aimed to prevent child marriage and support married girls to build life skills, improve literacy, and access services. Population Council staff mapped community resources and gathered social and demographic information on both boys and girls within communities, including evidence on their access to resources and risks of negative outcomes. They found that boys had better access to resources, while girls' risk of child marriage and other negative outcomes was far higher. By presenting this information to adult community members, program staff were able to illustrate why a girls' program was important and build trust within communities. 


\title{
How do economic and social pressures shape community norms about marriage, education, work, and gender roles?
}

\author{
Even when families generally support the idea of a new program, \\ they may worry it will distract girls from household chores or schoolwork.
}

In impoverished communities, competing priorities for girls' time may be an almost insurmountable challenge. Simple strategies like adjusting the timing of group meetings to avoid conflicts with girls' responsibilities may help ease concerns.

Beyond logistics, the idea that girls should attend a program may pose an implicit challenge to social norms, including how girls and boys should spend their time. Encouraging community members to critically examine how girls and boys use their time may encourage reflection and shift beliefs about girls' roles and their value to households and communities.

Where to find answers: Community mapping exercises can generate an inventory of resources such as schools, markets, and water sources, including their locations and when girls visit them. ${ }^{8}$ Programs can engage girls to conduct the community mapping. This information can help account for competition for girls' time and establish realistic goals for girls' enrollment and attendance. Interviews and focus groups can uncover the range of beliefs and perspectives on economic and social pressures adults and girls alike associate with marriage, schooling, or the value of girls' work in and outside of the home.

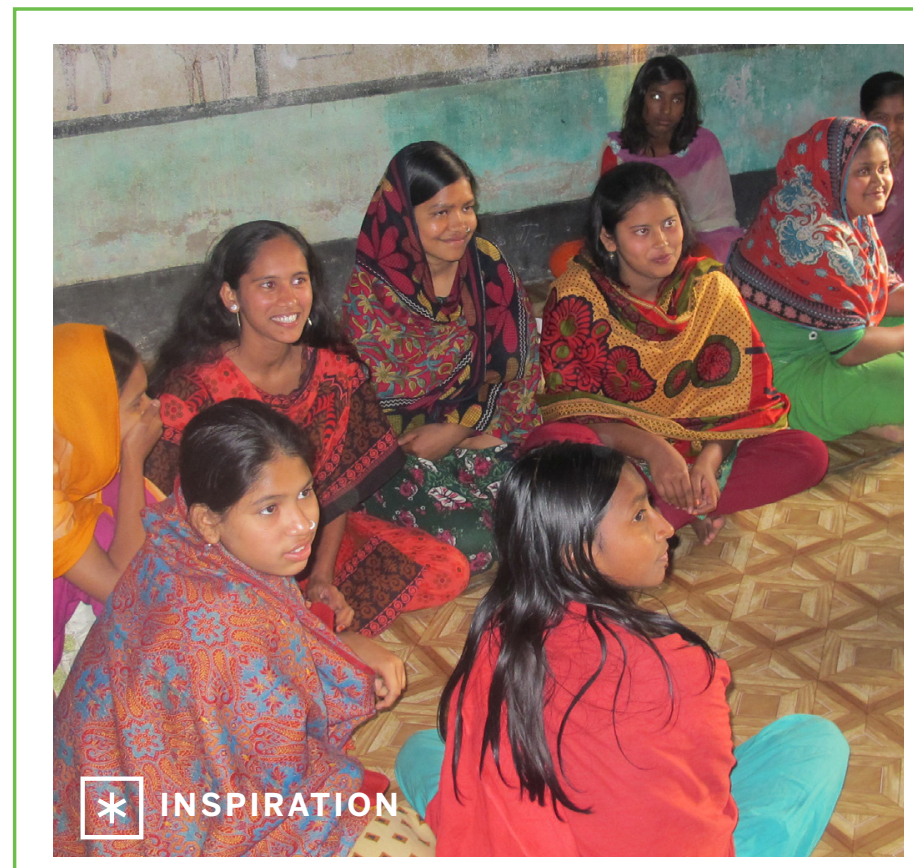

The Bangladeshi Association for Life Skills, Income, and Knowledge for Adolescents (BALIKA) project aimed to raise girls' age of marriage by introducing new possibilities for girls and enhancing their value to families and communities. ${ }^{9}$ The program held sessions in school classrooms that were newly equipped with computers, which girls were trained to use. Access to new technology helped allay parents' concerns that club sessions would distract girls from existing responsibilities without providing benefits in return.

Recognizing that change relies on both families' and influential community members' support, the program also engaged adults in ongoing dialogue on the value of girls' skills and completing their education before marriage. Girls' access to new skills was part of a coordinated strategy to encourage families to support girls while reducing the community-level social and economic pressures that sustained family desires to arrange marriages for their daughters at young ages.

\footnotetext{
8 Hallman, K. 2016. “Community Mapping Exercise” in Building Girls' Protective Assets: A Collection of Tools for Program Design. Population Council, popcouncil.org/uploads/pdfs/2016PGY_GirlsProtectiveAssetsTools.pdf

9 Amin, Sajeda et al. 2016. "Delaying Child Marriage Through Community-Based Skills Development Programs for Girls.” popcouncil.org/uploads/pdfs/2016PGY_BALIKA_EndlineReport.pdf
} 


\section{population COUNCIL \\ Ideas. Evidence. Impact.}

The Population Council helps strengthen the capacity of different actors to design, implement, and evaluate effective, scalable programs that build the health, social, economic, and cognitive assets of adolescent girls. To download the Council's series of practical tools and resources for girl-centered programming, visit: popcouncil.org/girl-centered-program-resources

\section{GIRL Center}

FOR INNOVATION, RESEARCH. AND LEARNING

The Girl Innovation, Research, and Learning (GIRL) Center generates, synthesizes, and translates evidence to transform the lives of adolescent girls popcouncil.org/girlcenter

Suggested citation: Blake, Sarah and Miriam Temin. 2019. “Understanding the Role of Communities in Programming for Adolescent Girls: More Than a Backdrop." New York: Population Council. 